\title{
Hábitos de consumo e impacto ambiental: como o consumidor lida com as necessidades de consumo do dia a dia
}

\author{
Habits of consumption and environmental impact: how the consumer handles with the consumption requirements of \\ everyday life
Maria Eloneide P. Ferreira', Cecilia C. S. Marsaro², Carla Maria Abido Valentini ${ }^{3}$, Rozilaine A. P. Pelegrine Gomes Faria ${ }^{4}$

\begin{abstract}
'Graduada em Tecnologia da Gestão Ambiental, Instituto Federal de Mato Grosso, Bela Vista, Brasil
${ }^{2}$ Graduanda em Tecnologia de Gestão Ambiental, Instituto Federal de Mato Grosso, Bela Vista, Brasil

${ }^{3}$ Departamento de Química e Meio Ambiente, Instituto Federal de Mato Grosso, Bela Vista, Brasil
\end{abstract}

\begin{abstract}
Resumo
Neste trabalho objetivou-se avaliar o perfil sócio-econômico das pessoas economicamente ativas com idade entre 18 e 30 anos no município de Cuiabá-MT, e a influência da propaganda no que se refere ao poder de compra levando-se em consideração a potencialidade do impacto ambiental ocasionado pelos maus hábitos de consumo. A pesquisa foi desenvolvida utilizando um questionário estruturado de 11 questões objetivas e uma subjetiva, onde foram avaliados a faixa de renda, nível educacional, débitos sobre a renda, grau de representatividade na decisão de compra, influencia da propaganda e qual a atividade de compra que produz mais resíduo. A maioria (55\%) dos entrevistados é do sexo feminino, tem ensino médio completo (28\%), 59\% tem faixa de renda de até 1 salário mínimo, $46 \%$ compromete acima de $70 \%$ da renda com despesas. O preço foi fator determinante na decisão de compra para a maioria dos entrevistados em diferentes níveis educacionais. Todos os entrevistados, independente do nível de escolaridade, citaram a alimentação e compras em supermercados como atividades que geram a maior quantidade de resíduo, após o consumo. A propaganda influencia na decisão da compra em $73 \%$ dos entrevistados. Os indivíduos mais jovens e com menor escolaridade, por necessidade de comprometer uma parte da renda com a aquisição de itens básicos para a sobrevivência, acabam comprometendo grande parte da renda com despesas básicas. Campanhas educacionais voltadas para economia dos recursos naturais poderiam ser utilizadas na tentativa de diminuir o impacto ambiental gerado pelo consumo exagerado.
\end{abstract}

Palavras-chave: Escolaridade, educação e sustentabilidade.

\begin{abstract}
This work aimed to evaluate the socio-economic profile of economically active people aged between 18 and 30 years and the influence of advertising in relation to purchasing power taking into account the potential environmental impact caused by the bad habits of consumption. The research was conducted using a questionnaire structured with 11 objective questions and one subjective question. The income level, educational level, debts on income, level of representation in the purchase decision, advertising and which influences over purchasing activity that produces more residue. The majority (55\%) of the respondents were female, had completed secondary education (28\%), 59\% have income range up to one monthly wage, $46 \%$ committed over $70 \%$ of their monthly income with debts. The price was the determining factor in the purchase decision for most respondents at different educational levels. All respondents, regardless of education level, cited food and shopping in supermarkets as activities that generate the greatest amount of residue after consumption. The advertising influences the buying decision in $73 \%$ of respondents. Younger individuals and with low educational level individuals need to undertake a portion of their income on the purchase of basic items for survival, end up compromising much of the income with basic expenses. Educational campaigns focused on natural resource economics could be used reducing the environmental impact generated by the overconsumption.
\end{abstract}

Keywords: Schooling: education and sustainability. 


\section{INTRODUÇÃO}

O modelo econômico adotado atualmente pelas sociedades proporciona e induz a um alto padrão de consumo, que, mesmo ao alcance de poucos, é insustentável pelos danos que acarreta para o meio ambiente. Diante desse cenário, para que o desenvolvimento siga no caminho da sustentabilidade é preciso alterar os padrões de consumo (GOMES, 2006).

Porém, hoje fazer compras é uma atitude bem vista e até incentivada pela sociedade, a percepção do problema sobre padrão de consumo muitas vezes só acontece quando o endividamento já se tornou extremo. O que acontece com consumidores endividados é ter que reduzir ou cortar uma série de gastos com alimentação, vestuário e outras despesas. E esta situação acaba não estabelecendo certo grau de criticidade com que está sendo nos ofertado, pois embora alguns indivíduos tenham a informação, eles acabam não a praticando (ALMEIDA, 2003).

Ainda, de acordo com Spínola (2001), é preciso adotar a ética da vida sustentável, em que os consumidores deverão reexaminar seus valores e alterar seu comportamento. Ele explica que a sociedade deverá estimular os valores que apoiem esta ética e desencorajar aqueles modos de vida insustentáveis.

Nesse sentido, ressalta Canepa (2004): "Tem-se que ter sempre em mente que educação e cidadania são indissociáveis: quanto mais o cidadão for educado, em todos os níveis, mais será capaz de lutar e exigir seus direitos e cumprir seus deveres".

Logo a atuação da educação, torna-se a principal ferramenta disponível para essa reflexão de valores. Segundo Lima (1999), a opção de articular a educação e meio ambiente deve-se a uma série de motivos associados. Ele coloca a importância da educação enquanto instrumento privilegiado de humanização, socialização e direcionamento social.

Está claro que, como toda prática social, ela guarda em si as possibilidades extremas de promover a liberdade ou a opressão, de transformar ou conservar a ordem socialmente estabelecida. Nesse sentido, embora não seja único agente possível de mudança social, é um dentre outros processos onde essa potencialidade se apresenta (LIMA, 2003).

É importante ressaltar que a educação não deve ser entendida como um processo que é capaz de resolver todos os problemas socioambientais, entretanto, não é possível encorajar a mudança social e ambiental sem a integração com a dimensão educacional (REZENDE e OLIVEIRA, 2010).

E por isso a Educação Ambiental deve abranger o homem em todos os planos de sua realidade: na dimensão da vida, na dimensão social e democrática, intelectual e reflexiva, na dimensão da liberdade sendo preciso capacitar o cidadão para uma participação ativa na definição dos modelos de desenvolvimento sustentável, sem perder de vista a complexidade das determinações e inter-relações de sua dimensão biosférica (SED-SC, 1997).

É importante ligar as ações de educação ambiental ao ensino formal, o que poderá dar um caráter mais permanente ao tema, tornando o processo cíclico e evolutivo (LOPES, 2009).

Portanto, neste trabalho objetivou-se avaliar o perfil sócio-econômico das pessoas economicamente ativas com idade entre 18 e 30 anos na cidade de Cuiabá-MT e a influência da propaganda no que se refere ao poder de compra levando-se em consideração a potencialidade do impacto ambiental ocasionado pelos maus hábitos de consumo.

\section{METODOLOGIA}

\section{I Coleta dos DADOS}

A pesquisa foi desenvolvida através da aplicação de questionários estruturados com onze questões objetivas e uma questão subjetiva numa população economicamente ativa com idade entre 18 e 30 anos conforme metodologia aplicada por Santos (2010). Os visitantes foram abordados e de maneira voluntária se dispuseram responder as perguntas, de maneira a preservar a identidade do entrevistado. O estudo foi desenvolvido sob cuidados éticos conforme determinação do Conselho Nacional de Saúde-Resolução n. 196/1996 (BRASIL, 1996).

A amostra foi formada por 100 pessoas moradoras da cidade de Cuiabá-MT. Foram avaliados a faixa de renda, nível educacional, percentual de débitos sobre a renda, mensuração sobre ter se arre- 
pendido ou não em ter comprado um produto; interesse em se informar sobre o processo de fabricação do produto, grau de representatividade na decisão de compra, influencia da propaganda e noção sobre qual atividade de compra efetuada que produz mais resíduo.

\subsection{ANÁLISES DOS DADOS}

Os dados foram analisados através de estatística descritiva demonstrados comparativamente em gráficos; a questão subjetiva foi aninhada por grupo de resposta parecido e quantificadas aquelas palavras de maior freqüência. Todos os dados foram comparados com literatura específica.

\section{RESULTADOS E DISCUSSÃO}

A referida pesquisa identificou que entre os entrevistados $45 \%$ são do sexo masculino e $55 \%$ do sexo feminino. Entre os entrevistados, houve uma ampla diferença de nível educacional, com maior representatividade de $28 \%$ dos entrevistados com ensino médio completo, seguido de nível superior (16\%) e em menor representatividade, pós - graduação 8\% (Figura 1).

Figura 1. Nível de escolaridade dos entrevistados

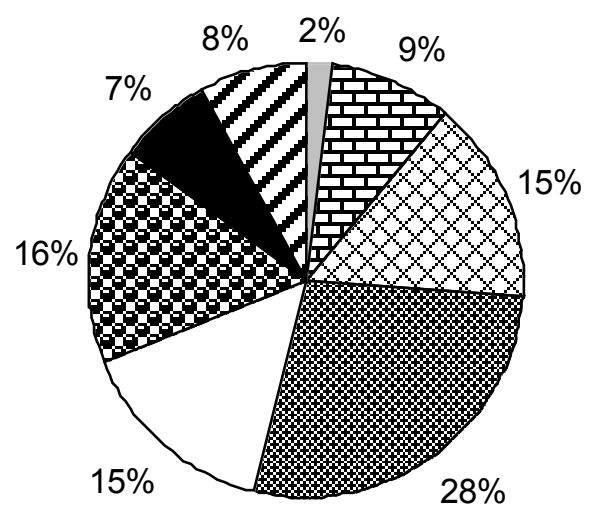

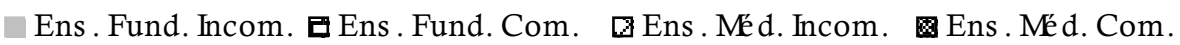

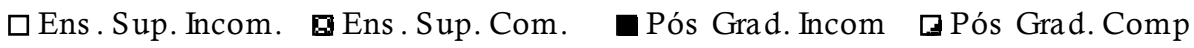

Dentre a população amostrada, observa-se um menor comprometimento da renda, conforme aumenta-se o nível de escolaridade. A maioria dos indivíduos entrevistados com pós-graduação completa (69\%) compromete até $30 \%$ da sua renda em despesas enquanto que os indivíduos com ensino fundamental incompleto (46\%) comprometem mais que $70 \%$ da sua renda em dívidas (Tabela 1). Pode-se entender que os indivíduos de baixa escolaridade com faixa de renda limitada de até dois salários mínimos, ocasionalmente em qualquer compra de um objeto, seja por necessidade ou não, comprometerá um grande percentual de sua renda.

É possível que a baixa escolaridade impacte diretamente sobre a captação de recursos financeiros e o endividamento seja ocasionado pelo impacto no custeio com despesas básicas como alimentação e saúde. Um menor poder aquisitivo bem como maior endividamento estariam diretamente relacionados com o nível educacional, sugerindo que a educação interfere na forma direta do uso da renda real (Langoni et al., 2005). 
Tabela 1. Relação entre nível de escolaridade e percentual de despesas sobre a renda

\begin{tabular}{l|c|c|c}
\hline \multirow{2}{*}{ Nível Educacional } & \multicolumn{3}{|c}{ Percentual de Despesas Sobre a Renda } \\
\cline { 2 - 4 } & $\mathbf{7 0 \%}$ & $70 \% \geq X \geq 50 \%$ & $50 \%<\mathrm{x}<30 \%$ \\
\hline E. F. Incompleto & $\mathbf{4 6 \%}$ & $31 \%$ & $23 \%$ \\
\hline E. F. Completo & $41 \%$ & $28 \%$ & $31 \%$ \\
\hline E. M. Incompleto & $37 \%$ & $35 \%$ & $28 \%$ \\
\hline E. M. Completo & $29 \%$ & $27 \%$ & $44 \%$ \\
\hline E. S. Incompleto & $31 \%$ & $24 \%$ & $45 \%$ \\
\hline E. S. Completo & $24 \%$ & $27 \%$ & $59 \%$ \\
\hline Pós- graduação Inc. & $19 \%$ & $22 \%$ & $\mathbf{6 9} \%$ \\
\hline Pós- graduação Comp. & $\mathbf{1 2} \%$ & $19 \%$ & \\
\hline
\end{tabular}

E.F.:Ensino Fundamental; E.M.:Ensino Médio; E.S.: Ensino Superior

Quanto ao critério de escolha no momento em adquirir um produto, a marca do produto apresentou a menor representatividade (9\%) para indivíduos de menor escolaridade. A necessidade na aquisição do bem e o preço, quando somados, foram critérios decisivos para os entrevistados de menor escolaridade enquanto que os critérios preço e qualidade foram decisivos para consumidores de maior escolaridade (Tabela 2).

Tabela 2- Relação entre nível de escolaridade e decisão de compra

\begin{tabular}{l|c|c|c|c|c}
\hline \multirow{2}{*}{\multicolumn{1}{c|}{ Nível Educacional }} & \multicolumn{5}{c}{ Representatividade da Decisão de Compra } \\
\cline { 2 - 6 } & Necessidade & Marca & Preço & Qualidade & Total \\
\hline E. F. Incompleto & $\mathbf{2 9 \%}$ & $\mathbf{9 \%}$ & $\mathbf{3 2} \%$ & $30 \%$ & $100 \%$ \\
\hline E. F. Completo & $\mathbf{3 5 \%}$ & $10 \%$ & $\mathbf{4 0 \%}$ & $15 \%$ & $100 \%$ \\
\hline E. M. Incompleto & $19 \%$ & $22 \%$ & $27 \%$ & $32 \%$ & $100 \%$ \\
\hline E. M. Completo & $21 \%$ & $15 \%$ & $34 \%$ & $30 \%$ & $100 \%$ \\
\hline E. S.Superior Incompleto & $12 \%$ & $30 \%$ & $37 \%$ & $21 \%$ & $100 \%$ \\
\hline E. S.Superior Completo & $8 \%$ & $12 \%$ & $39 \%$ & $41 \%$ & $100 \%$ \\
\hline Pós-graduação Incompleta & $13 \%$ & $7 \%$ & $\mathbf{4 3 \%}$ & $\mathbf{3 7 \%}$ & $100 \%$ \\
\hline Pós-graduação Completa & $10 \%$ & $14 \%$ & $\mathbf{3 9 \%}$ & $\mathbf{3 7 \%}$ & $100 \%$ \\
\hline
\end{tabular}

E.F.:Ensino Fundamental; E.M.:Ensino Médio; E.S.: Ensino Superior

A propaganda pode exercer alguma influência sobre a decisão de compra do consumidor, $73 \%$ dos entrevistados afirmaram que às vezes são influenciados pela propaganda na decisão de compra (Figura 2). Segundo Engel et al. (1995), algumas variáveis influenciam na decisão de compra do consumidor podendo estar relacionadas com cultura, estilo de vida, personalidade, classe social, mudança de atitude, aprendizagem e comportamento (Figura 2).

O grupo de ensino fundamental incompleto (59\%) tem sua renda de até um salário mínimo (Tabela 3). Além disso, os entrevistados com ensino médio completo apresentam $52 \%$ com renda também limitada a um salário mínimo.

Para o grupo de ensino fundamental completo, 35\% têm renda entre dois a quatro salários mínimos, o que facilita e aumenta seu poder de compra. Pode-se sugerir que esses indivíduos estejam 


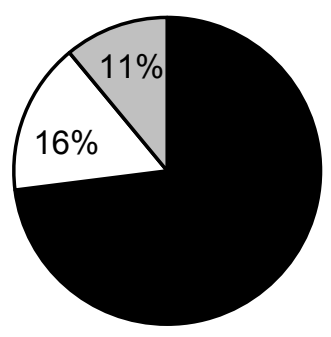

Às vezes $\square$ Nunca $\square$ Não sei responder

Figura 2. Nível de influência da propaganda sobre os entrevistados

presentes no mercado de trabalho a mais tempo, proporcionando uma melhoria na renda e assim aumentando seu poder de compra. Andrade \& Dachs (2007) afirmam que o acesso ao ensino fundamental, para idades menores não se condiciona com a renda familiar. No entanto, conforme aumenta-se o acesso a nível de escolaridades superiores, a renda familiar se condiciona como fator determinante no nível de escolaridade influenciando o poder de compra desses indivíduos. Comparando-se a faixa de renda de 2 a 4 salários mínimos, observa-se extremos no nível de escolaridade: o grupo com baixo nível de escolaridade apresentou percentual maior para renda de até 1 salário mínimo (59\%) enquanto que o grupo com nível superior completo, o percentual foi maior (60\%) para faixa entre 2 a 4 salários mínimos. Observação semelhante foi verificada por Andrade \& Dach (2007). O mesmo impacto do nível de escolaridade foi observado para indivíduos com pós graduação, com $60 \%$ dos entrevistados com uma renda de dois a quatro salários mínimos, havendo menor comprometimento de sua renda com as dívidas.

Tabela 3. Relação de nível de escolaridade e faixa de renda

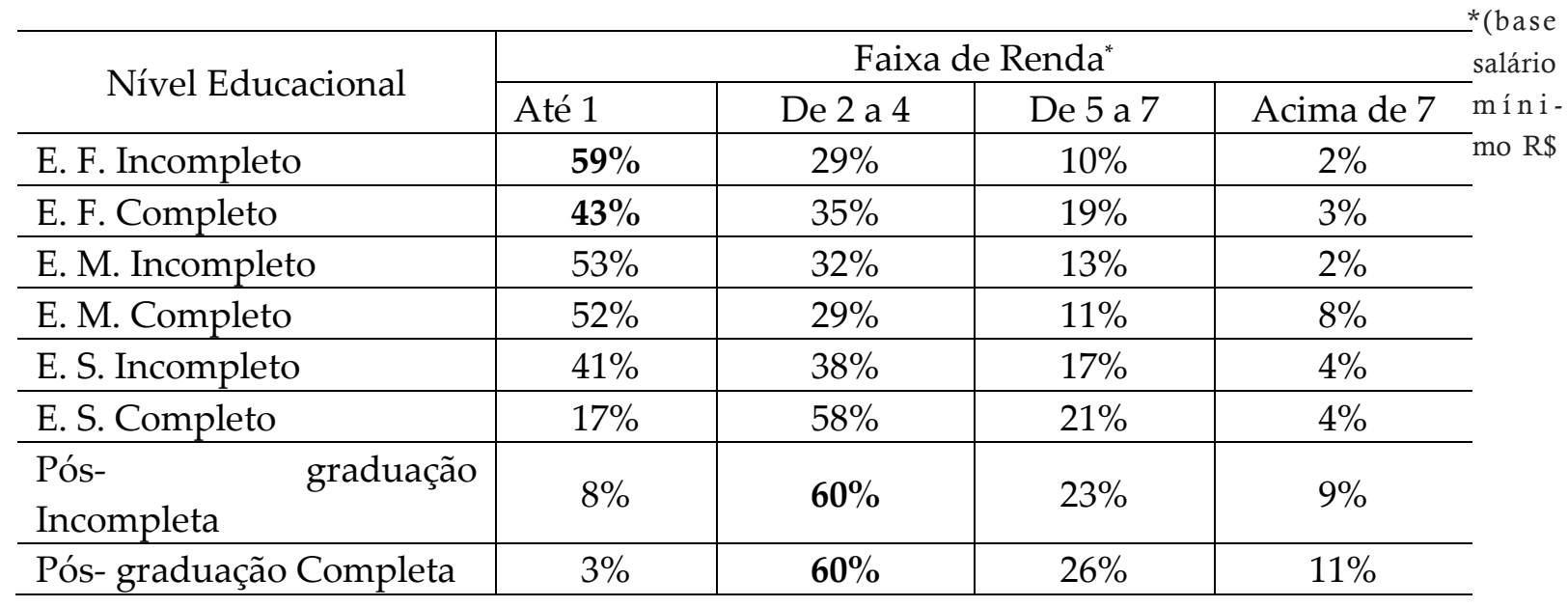

678,00); E.F.:Ensino Fundamental; E.M.:Ensino Médio; E.S.: Ensino Superior

Para Gomes (2006) o consumo excessivo se manifesta como resposta ao apelo da mídia, de que você necessita ter aquele produto e com a facilidade do credito no mercado, as pessoas acabam comprando produtos dos mais variados tipos e funções em formas de pagamentos cada vez mais facilitadas com isso favorece o individamento, além de fazer com que pessoas iludidas pelas propagandas acumulem itens não prioritários a suas vidas.

Isso também é visto em grupos de alta escolaridade, muitos com nivel superior tambem às vezes compram sem necessidade, simplesmente para agradar o próprio ego. Entretanto conforme os dados, por ter uma faixa de renda razoável, esses débitos acabam não afetando tanto o comprometimento de sua renda. 
Para Zambon et al. (2003) os estudos sobre o comportamento do consumidor não são novos. Ele veio nos revelar que existe outro padrão, um ideal infinitamente mais elevado. Isso para gerar em nós esse sentimento de inconformismo e descontentamento com o "sistema" que rege a vida. Esses sentimentos podem ser vistos de duas formas: na primeira instancia, com $36 \%$ dos entrevistados, relatam ter em algum momento um sentimento de arrependimento de ter comprado o produto e/ou objeto/serviço (Figura 3A). Mas existe um contraste de valores sentimentais e psicológicos, referente ao ato de comprar, como observado por Engel et al. (1995), pois se conforme a figura 3B, verifica-se que $49 \%$ dos entrevistados em algum momento estiveram angustiados ou se sentiram inferiores por não ter comprado seu objeto de desejo. Isso pode estar relacionado ao seu poder de compra estar baixo ou até mesmo por já ter boa parte da sua renda comprometida.

(A)

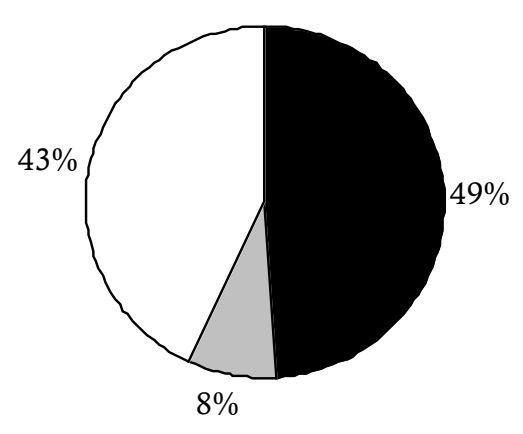

- Sim $\square$ Não $\square$ Às vezes
(B)

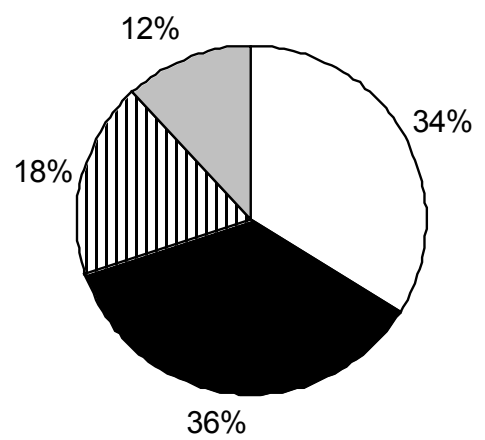

$\square$ Sempre $\square$ Às vezes $\square$ Raramente $\square$ Nunca

Figura 3. Sentimentos de arrependimento (A) e de angústia (B) surgidos nos entrevistados após momentos de compra

Zambon et al. (2003) defendem em seu trabalho que o consumidor, em sua definição, baseado na economia, acaba sendo uma unidade de consumo ou gasto e que isso influencia no gasto de sua família e em seu orçamento. Além disso, eles retratam que o comportamento compulsivo de comprar é hedonicamente complexo e que isso influencia em sérias conseqüências psicológicas.

Apesar dos dados da pesquisa comprovarem relações de nivel educacional, faixa salarial e débitos, o endividamento está presente em todas as classes sociais. Ter o hábito de compra se tornar normal a ponto das pessoas viverem com o orçamento estourado, o que pode ser chamado de "oneomania", que atinge as pessoas caracterizadas como compradoras compulsivas. Este sentimento é inevitável quando o individuo não estabelece o limite de parar de comprar.

Nesse sentido que Brandsma e Eppel (1997) relacionam questões econômicas e suas interferências nas ações cotidianas das pessoas, no qual ele discute em "Mudando os Padrões de Produção e Consumo".

Um processo de ambientalização e politização do consumo também podem ser observados, utilizando propostas e estratégias que enfatizam os padrões e niveis de consumo consciente frente à crise ambiental que enfrentamos. Alem disso, tratando-se de mudanças de padrões de consumo, os entrevistados disseram se preocupar sobre a forma que o produto foi produzido e qual o material utilizado. Novamente observa-se uma relação social entre o nível educacional e a percepção de querer conhecer o produto. Para o grupo de baixa escolaridade, verifica-se que $92 \%$ dos entrevistados não se interessam em saber o tipo do material, assim também este mesmo grupo $89 \%$ não tem interesse em conhecer o processo de produção. Entretanto os resultados para o grupo de nivel superior e pós-graduado, mostram que apenas $20 \%$ se interessam pela informação do produto (Tabela 4). Em estudo desenvolvido por Enoki et al. (2008), entrevistados com nivel de escolaridade maior estariam dispostos em pagar mais para adquirir produtos ecologicamente corretos, o que reforça a necessidade em cam- 
panhas em educação ambiental bem como incentivos em melhoria do nivel educacional em pessoas de menor nivel de escolaridade.

Tabela 4. Relação de entre o nível educacional e o nível de interesse em conhecer o material e/ou processo de fabricação

\begin{tabular}{l|c|c|c|c}
\hline \multirow{2}{*}{\multicolumn{1}{c}{ Nível Educacional }} & \multicolumn{4}{c}{ Você procura se informar } \\
\cline { 2 - 5 } & \multicolumn{2}{|c}{ Sobre o tipo de material } & \multicolumn{2}{c}{$\begin{array}{c}\text { Sobre Processo de } \\
\text { produção }\end{array}$} \\
\cline { 2 - 5 } & Sim & Não & Não & Sim \\
\hline E. F. Incompleto & $22 \%$ & $78 \%$ & $84 \%$ & $16 \%$ \\
\hline E. F. Completo & $8 \%$ & $92 \%$ & $89 \%$ & $11 \%$ \\
\hline E. M. Incompleto & $9 \%$ & $91 \%$ & $86 \%$ & $14 \%$ \\
\hline E. M. Completo & $13 \%$ & $87 \%$ & $90 \%$ & $10 \%$ \\
\hline E. S. Incompleto & $21 \%$ & $79 \%$ & $81 \%$ & $19 \%$ \\
\hline E. S. Completo & $18 \%$ & $82 \%$ & $83 \%$ & $17 \%$ \\
\hline Pós- graduação Incompleto & $23 \%$ & $77 \%$ & $78 \%$ & $22 \%$ \\
\hline Pós- graduação Completo & $20 \%$ & $80 \%$ & $79 \%$ & $21 \%$ \\
\hline
\end{tabular}

E.F.:Ensino Fundamental; E.M.:Ensino Médio; E.S.: Ensino Superior

O ser humano vive em busca de um meio ambiente em equilíbrio, mas suas atitudes de consumo excessivo o fazem caminhar em sentido oposto a esta busca (GOMES, 2006). O tipo de material utilizado na elaboração de um produto pode impactar o meio ambiente através dos residuos e subprodutos gerados com a decomposição/degradação. Por isso a educação ambiental entra como uma ferramenta incorporadora de novos hábitos, porque ela não mede grupo social e faixa de renda, mas sim pode ser inserida desde a educação de base como na educação superior.

Lopes et al. (2009) em seu trabalho e pesquisa de campo, observaram em uma escola pública que um grupo de alunos, por não ter conhecimento de educação ambiental e sustentabilidade, tinham hábitos de jogar lixos em lugares impróprios. Miranda e Joia (2004), também observaram que após conscientizá-los da questão ambiental e coleta seletiva, esses alunos se tornaram multiplicadores ambientais, levando para sua comunidade a organização da coleta seletiva.

Entretanto depois de alguns meses, Lopes et al. (2009), entrevistaram novamente esses alunos e perceberam que tinham conseguido sensibilizá-los na forma de tratar o lixo. Além disso, fazendo um comparativo entre os entrevistados deste trabalho, o consumo muitas vezes acaba gerando resíduo que não recebe um destino adequado.

Muitas vezes a própria percepção do indivíduo sobre geração do resíduo se restringe a compra de gêneros alimentícios. Entre os entrevistados, a maior representatividade, independente do nível de escolaridade, se restringiu a gêneros alimentícios e compras em supermercados (Tabela 5)

É importante perceber que entre os extremos dos níveis de escolaridade de escolaridade, ensino fundamental incompleto e pós-graduação completo, visualizam de maneira proporcional a geração de resíduo entre os setores de alimentação, supermercado e lojas de roupas. As respostas, obtidas de questão aberta, permitiu observar a percepção no rumo de atividade que mais gera resíduo.

Conforme o hábito de consumo de cada grupo, atividades de consumo mais lembradas, como alimentação e supermercado; sugere a importância da incorporação de novos hábitos e estímulo por parte dos veículos de comunicação, sobre incentivos para a separação dos resíduos no âmbito domiciliar, uma vez que os resíduos domésticos (alimentação) impactam diretamente o meio ambiente além de serem alvos de vetores, propiciando danos para a saúde publica.

Neste sentido, a educação ambiental possui papel fundamental na formulação de uma nova mentalidade. De modo mais específico, a educação para o consumo é elemento-chave na conscientização da população (GOMES, 2006). 
Tabela 5. Relação de nível de escolaridade e atividade de compra

\begin{tabular}{|c|c|c|c|c|}
\hline \multirow[b]{2}{*}{ Nível Educacional } & \multicolumn{4}{|c|}{$\begin{array}{l}\text { Qual atividade que você exerce que apresenta maior } \\
\text { quantidade de lixo (resíduo)? }\end{array}$} \\
\hline & Alimentação & Supermercado & $\begin{array}{l}\text { Lojas } \\
\text { de } \\
\text { roupas } \\
\end{array}$ & $\begin{array}{c}\text { Produtos } \\
\text { adquiridos com } \\
\text { menos frequência }\end{array}$ \\
\hline E. F. Incompleto & $26 \%$ & $30 \%$ & $23 \%$ & $21 \%$ \\
\hline E. F. Completo & $39 \%$ & $29 \%$ & $12 \%$ & $20 \%$ \\
\hline E. M. Incompleto & $33 \%$ & $42 \%$ & $15 \%$ & $10 \%$ \\
\hline E. M. Completo & $39 \%$ & $29 \%$ & $9 \%$ & $23 \%$ \\
\hline E. S. Incompleto & $35 \%$ & $39 \%$ & $11 \%$ & $15 \%$ \\
\hline E. S. Completo & $38 \%$ & $35 \%$ & $19 \%$ & $8 \%$ \\
\hline Pós-graduação Incompleto & $29 \%$ & $41 \%$ & $18 \%$ & $12 \%$ \\
\hline Pós-graduação Completo & $31 \%$ & $34 \%$ & $20 \%$ & $15 \%$ \\
\hline
\end{tabular}

E.F.:Ensino Fundamental; E.M.:Ensino Médio; E.S.: Ensino Superior

Apesar do consumo exagerado frente ao poder aquisitivo, notou-se que o principal elemento para mobilização de um consumo consciente e ético, esta ligado ao nível educacional de cada individuo. Para isso a educação deve ser entendida como um dos instrumentos básicos e indispensáveis à sustentabilidade dos processos de mudança de hábitos das pessoas. A educação ambiental traz o foco para a importância de capacitar indivíduos a partir do universo cognitivo e comunicativo, usando de questões sócio-políticas para ações implementadas, em relações intersubjetivas e intergrupais, suas diferenciações socioeconômicas, culturais e ideológicas.

Portanto e educação ambiental deve ser inserida em todos os grupos sociais e níveis educacionais, como uma disciplina contribuinte de novos aprendizados, estabelecendo processos de reflexão-ação-reflexão; criando uma rede de aprendizagem baseado na comunidade como espaço a ser trabalhado.

Por isso a educação ambiental é uma grande e importante ferramenta para capacitar o cidadão para uma participação ativa na sociedade, buscando o consumo consciente, o equilíbrio financeiro e a formação de um consumidor ético e responsável que implica necessariamente uma nova postura diante do ato de consumir e um maior conhecimento sobre o consumo sustentável.

\section{CONCLUSÃO}

Os indivíduos mais jovens e com menor escolaridade, por necessidade de comprometer uma parte da renda com a aquisição de itens básicos para a sobrevivência, acabam comprometendo grande parte da renda com despesas básicas.

A propaganda exerce certa influência na decisão de compra, porém a educação ambiental poderia ser abordada, entre os meios de divulgação, como ferramenta para conscientizar a população sobre o impacto do consumo no meio ambiente.

\section{REFERÊNCIAS}

ALMEIDA, J.B. de. Manual de direito do consumidor. São Paulo: Saraiva, 2003. 214p.

ANDRADE, C.Y.; DACH, J.N.W. Acesso à educação por faixas etárias segundo renda e raça/cor. Cadernos de Pesquisa, vol. 37, n.131, p.399-422, 2007.

BRANDSMA, E. H.; EPPEL, J. Produção e consumo sustentáveis: um enfoque internacional. In: RIBEMBOIM, J (org). Mudando os Padrões de Produção e Consumo. Brasília, IBAMA, 1997, p. 112. 
BRASIL, Resolução 196 de 1996. Diretrizes e normas regulamentadoras de pesquisas envolvendo seres humanos. Conselho Nacional de Saúde. Disponível em:< http://conselho.saude.gov.br/comissao/conep/resolucao. html> Último acesso em: 09 jun 2013.

CANEPA, C. Educação ambiental: ferramenta para a criação de uma nova consciência planetária. Revista de Direito Constitucional e Internacional, vol. 12, n. 48, p. 158-166, 2004.

ENGEL, J. F.; BLACKWELL, R. D.; MINIARD, P. W. Consumer behavior, $8^{\mathrm{a} e d .}$ Forth Worth: Dryden Press, 1995.

ENOKI, P. A.; ADUM, S. H. N.; FERREIRA, M. Z.; AURELIANO, C. A.; VALDEVINO, S. L.; SILVA, A. A. Estratégias de marketing verde na percepção de compra dos consumidores na grande São Paulo. Revista Jovens Pesquisadores, vol. 5, n. 1, p. 58-74, 2008.

GOMES, D.V. Educação para o Consumo Ético e Sustentável. Revista Eletrônica do Mestrado em Educação Ambiental, vol.16, p 18-31, 2006.

LANGONI, C. G. Distribuição de Renda e Desenvolvimento Econômico do Brasil. $3^{\text {a }}$ ed. Rio de Janeiro: Editora FGV, 2005. 280p.

LIMA, G.F. da C. Questão ambiental e educação: contribuições para o debate. Ambiente e Sociedade, vol.0, n.5. p 135-153, 1999.

LIMA, G.F. da C. O discurso da sustentabilidade e suas implicações para a educação. Ambiente e Sociedade, vol.6, n. 2, p 99-119, 2003.

LOPES, W.; BISPO, W.; CARVALHO, J. Gestão ambiental. Projetos 2009-1/1. Palmas - TO, Faculdade Católica do Tocantins, 2009. Educação Ambiental nas Escolas: uma estratégia de mudança efetiva. Disponível em: http://www.catolica-to.edu.br/portal/portal/downloads/docs_gestaoambiental/projetos2009-1/1-periodo/ Educacao_ambiental_nas_escolas_uma_estrategia_de_mudanca_efetiva.pdf . Último acesso em: 26 jul 2013.

MIRANDA, E.P.; JOIA, P.R. A educação Ambiental Inserida na Produção de Resíduos Sólidos Domiciliares Urbanos de Aquidauana- MS. In: SIMPÓSIO SOBRE RECURSOS NATURAIS E SOCIOECONÔMICOS DO PANTANAL, IV, 2004. Corumbá- MS. Resumos...Corumbá- MS/ UFMS: UFMS, 2004. p 202.

REZENDE, V.A.; OLIVEIRA, D.E.R. Capitalismo, Relação Homem Natureza e Educação: Reflexões sobre a crise socioambiental. In: Colóquio Internacional: educação e contemporaneidade, IV, 2010. Anais, Laranjeiras- SE, 2010. p1-15.

SANTOS, J.M. O apelo ecológico na propaganda como fator de influência na atitude de compra do consumidor: um estudo experimental. 2010, 120f. Dissertação (mestrado) - Escola Brasileira de Administração Pública e de Empresas, Centro de Formação Acadêmica e Pesquisa: Rio de Janeiro, 2010.

SEDSC. Secretaria de Educação de Santa Catarina. Proposta Curricular de Santa Catarina. Versão Preliminar. SED/SC, Florianópolis, 1997. 15p.

SPÍNOLA, A.L. Consumo sustentável: o alto custo dos produtos que consumimos. Revista de Direito Ambiental, vol. 6, n. 24, p. 209-216, 2001.

ZAMBON, M.S.; BENEVIDES, G.; GIULIANI, A.C. CONGRESSO administração. Extensão, 2003. Alfenas- BH, Faculdade de administração, 2003. Comportamento do Consumidor no Varejo: Compra por Impulso e Dissonância Cognitiva. Disponível em: http://www.unifenas.br/extensao/administracao/iicongresso/080. htm . Último acesso em: 16 ago 2013. 